\title{
Estimando a espessura de um aterro de RSU pelo método MASW
}

Otávio Coaracy Brasil Gandolfo - gandolfo@ipt.br Instituto de Pesquisas Tecnológicas de São Paulo - IPT

\section{Copyright 2014, SBGf - Sociedade Brasileira de Geofísica}

Este texto foi preparado para a apresentação no VI Simpósio Brasileiro de Geofísica, Porto Alegre, 14 a 16 de outubro de 2014. Seu conteúdo foi revisado pelo Comitê Técnico do VI SimBGf, mas não necessariamente representa a opinião da SBGf ou de seus associados. É proibida a reprodução total ou parcial deste material para propósitos comerciais sem prévia autorização da SBGf.

\section{Abstract}

Seismic surveys carried out in municipal solid waste (MSW) landfills are less common than other geophysical methods like resistivity, GPR and electromagnetics. This paper presents the results of a geophysical survey using the Multichannel Analysis of Surface Waves (MASW) method carried out in a sanitary landfill. The results obtained $\left(V_{s}\right.$ profile with depth) was compared with the thickness of the landfill estimated by engineering and showed to be a promising technique to thickness evaluations in sanitary landfills.

\section{Introdução}

Em aterros de Resíduos Sólidos Urbanos (RSU) diversos métodos geofísicos já vêm sendo rotineiramente utilizados com o objetivo de caracterização hidrogeológica e no mapeamento de anomalias condutivas associadas a possíveis plumas de contaminantes em subsuperfície. Nestes ambientes, os métodos sísmicos ainda vêm sendo pouco utilizados. Entretanto, a sísmica pode ser empregada para a estimativa da espessura do corpo do aterro, informações muita vezes não disponíveis em uma avaliação ambiental, assim como na obtenção de módulos elásticos dinâmicos, parâmetros importante nos estudos de estabilidade de aterros.

A aplicação de métodos indiretos de investigação tornase ainda mais importante devido à inerente dificuldade de qualquer tipo de investigação direta em aterros de resíduos sólidos.

Este trabalho apresenta os resultados de um levantamento sísmico realizado em um aterro de RSU, utilizando o método MASW, com o objetivo de estimar a sua espessura.

\section{Levantamentos sísmicos em aterros de RSU}

Franco et al. (1995) realizaram levantamentos de refração sísmica no aterro sanitário de Brasília-DF, com o objetivo de determinar a profundidade do nível d'água e a espessura do lixo.

Malagutti et al. (1997) realizaram levantamento de refração sísmica no aterro sanitário de Rio Claro-SP, com o objetivo de determinar a profundidade do substrato do aterro para avaliação da espessura de lixo no local. Tandel et al. (1998), nesta mesma área de estudo e utilizando dados de refração sísmica, definiu as espessuras e a geometria do aterro.

Carvalho et al. (1998) e Carvalho (1999) realizaram ensaios crosshole no aterro sanitário Bandeirantes localizado no município de São Paulo-SP, com o objetivo de determinação dos parâmetros dinâmicos.

Com relação ao emprego de ensaios sísmicos em aterros de RSU utilizando ondas superficiais, podem ser citados os seguintes trabalhos: Kavazanjian et al. (1994, 1996), Rix et al. (1998) e Pereira et al. (2001) que utilizaram o método SASW; Sahadewa et al. (2011) que utilizaram os métodos MASW e o Microtremor Analysis Method.

\section{Os métodos das ondas superficiais}

Os métodos que utilizam as ondas superficiais se baseiam fundamentalmente nas propriedades da dispersão. O fenômeno da dispersão ocorre em um meio heterogêneo e estratificado, que apresente diferentes valores de velocidades de propagação das ondas sísmicas, situação típica encontrada em aterros de RSU. A energia (ou amplitude) das ondas superficiais decai exponencialmente com o aumento da profundidade. Grandes comprimentos de onda propagam-se em maiores profundidades e fornecem informações das velocidades das camadas mais profundas. De maneira contrária, pequenos comprimentos de onda propagam-se mais próximos à superfície e são influenciados pelas velocidades das camadas mais rasas. A relação entre velocidade de fase e a frequência (ou comprimento de onda) é denominada de curva de dispersão.

O método utiliza principalmente as ondas do tipo Rayleigh, que estão sempre presentes em um registro sísmico. Podem ser geradas por uma fonte do tipo "ativa" (marretas ou queda de pesos). Os ensaios são concebidos para se detectar este tipo de onda e, após o processamento e a inversão dos dados, obter-se um perfil 1D com a variação da velocidade da onda de cisalhamento $\left(V_{s}\right)$ com a profundidade em uma posição atribuída ao centro do arranjo (Figura 1). 


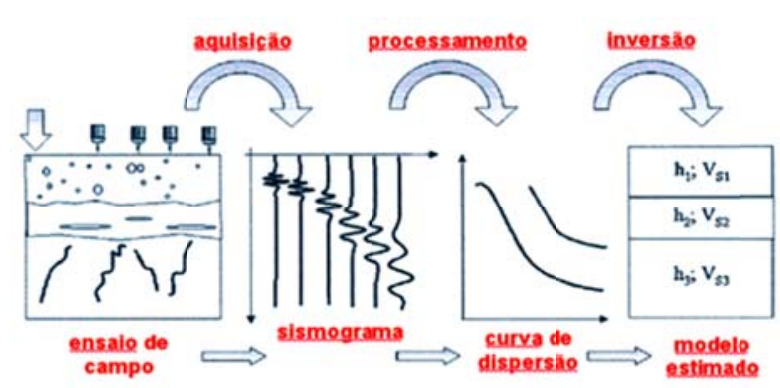

Figura 1 - llustração das etapas de um ensaio MASW (modificado de Strobbia, 2003).

Dentre alguns ensaios que utilizam ondas superficiais, destacam-se o SASW (Spectral Analysis of Surface Waves ou Análise Espectral de Ondas Superficiais) e o MASW (Multichannel Analysis of Surface Waves).

O método SASW utiliza apenas dois sensores para a aquisição dos dados. Já o método MASW, desenvolvido mais recentemente, utiliza múltiplos receptores. A ideia de aquisição com múltiplos canais, na qual a aquisição dos dados em campo é consideravelmente mais rápida, vem contribuindo para o desenvolvimento deste método.

\section{Levantamento de campo}

A aquisição dos dados foi realizada em um aterro sanitário que estava em processo de encerramento, localizado no município de Itapira-SP (Figura 2).

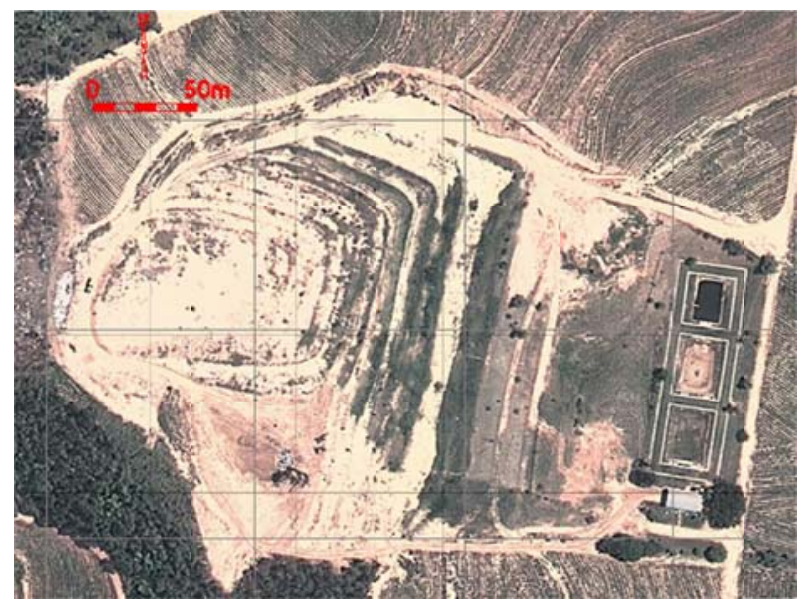

Figura 2 - Aterro sanitário de Itapira (Imagem Google, 2013).

$\mathrm{Na}$ área do aterro ocorrem rochas do denominado Bloco Itapira, predominantemente migmatitos e gnaisses. Sobrepostos às rochas cristalinas, ocorrem solos residuais (siltes arenosos) oriundos do intemperismo destas rochas, preservando as estruturas pretéritas tais como a xistosidade (IPT, 1998).

O levantamento MASW foi realizado utilizando um arranjo de 24 geofones de $4,5 \mathrm{~Hz}$ (componente vertical) espaçados entre si de $2 \mathrm{~m}$. Para o registro dos dados foi utilizado um sismógrafo modelo Geode, fabricado pela Geometrics.
Para a geração das ondas superficiais foi utilizada uma marreta de $5 \mathrm{~kg}$ batendo contra uma placa metálica posicionada sobre o solo. O arranjo foi posicionado sobre uma das bermas do aterro (Foto 1 ).

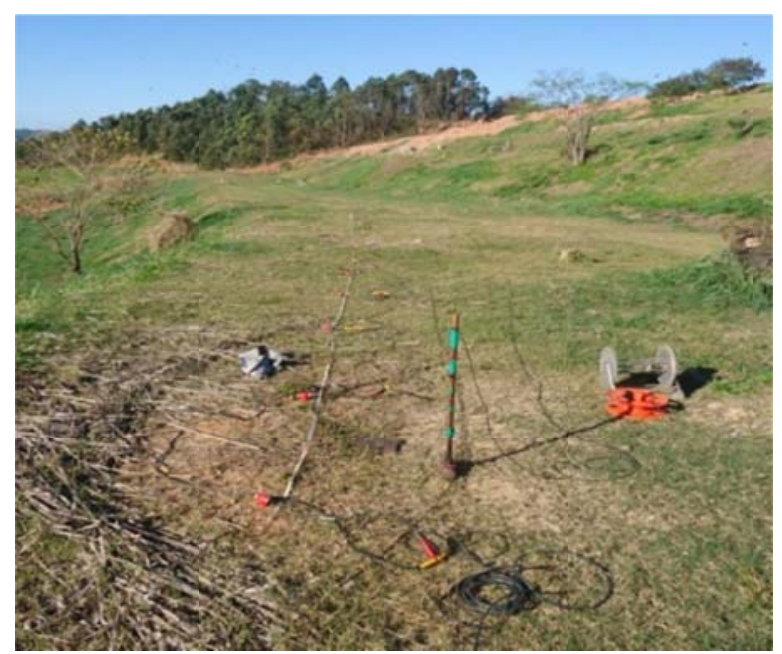

Foto 1 - Ensaio MASW realizado no aterro de Itapira.

Os sismogramas foram adquiridos utilizando-se três "offsets" mínimos (distância da fonte ao primeiro geofone): $5 \mathrm{~m}, 10 \mathrm{~m}$ e $15 \mathrm{~m}$.

\section{Resultados}

A Figura 3 apresenta um sismograma adquirido na área de estudo e o correspondente espectro de dispersão. Os dados foram processados no programa SeisImager/SW.

A curva de dispersão interpretada e o modelo 1D obtido por inversão dos dados são apresentados na Figura 4. No modelo podem ser observados valores de velocidade da onda S extremamente baixos (da ordem de $100 \mathrm{~m} / \mathrm{s}$ ) da superfície até aproximadamente $10 \mathrm{~m}$ de profundidade, no corpo de aterro de RSU.

$\mathrm{O}$ aumento de $\mathrm{V}_{\mathrm{S}}$ que ocorre abaixo desta profundidade foi interpretado como a base do aterro (terreno natural).

No plano de encerramento do aterro de Itapira foram feitas análises das condições de sua estabilidade, quando puderam ser obtidas informações pretéritas do contato dos resíduos sólidos com o terreno natural (IPT, 1998) e a atual geometria externa do aterro, obtida por meio de levantamento topográfico (IPT, 2014).

A partir destas informações foi possível a estimativa das espessuras do aterro e a comparação destes dados com os modelos obtidos pelos levantamentos geofísicos.

No local onde foi realizado o ensaio MASW, cujo resultado é apresentado neste trabalho, a espessura do aterro de RSU estimada pela engenharia foi de $12,1 \mathrm{~m}$, bem próxima da espessura interpretada com base no modelo de $V_{S}$ apresentado na Figura 4, que foi $10,4 \mathrm{~m}$.

A Figura 5 mostra uma seção do aterro sanitário sobre a qual foi inserido o modelo de $V_{S}$ versus profundidade correspondente ao local onde foi realizado o ensaio MASW. 


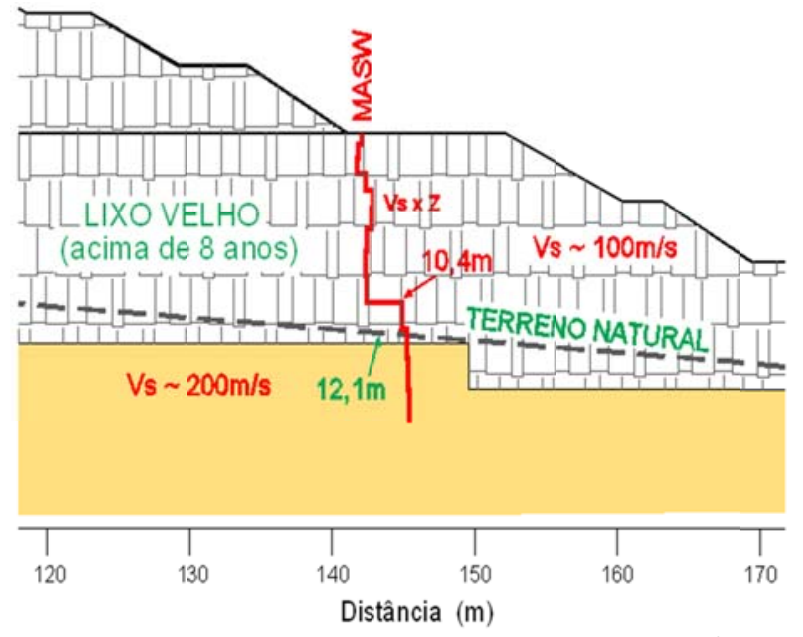

Figura 5 - llustração de um corte do aterro onde foi realizado o ensaio MASW. Estão assinaladas na seção as espessuras estimadas pela engenharia $(12,1 \mathrm{~m})$ e pelo modelo de $V_{S} \times$ profundidade $(10,4 \mathrm{~m})$.

\section{Conclusões}

O método MASW mostrou ser uma alternativa viável para determinação da espessura de um aterro de RSU, devido ao bom contraste de velocidades das ondas $S$ geralmente verificado entre 0 corpo do aterro sobrejacente e o substrato.

As boas condições de compactação no local onde o ensaio foi realizado (lixo velho, depositado há mais de 8 anos) podem ter contribuído para a qualidade dos registros obtidos em campo.

\section{Referências}

Carvalho, M. F.; Dourado, J. C.; Cordeiro, R. P.; Vilar, O. $M$, 1998. Determinação dos módulos dinâmicos para resíduos sólidos urbanos empregando ensaios crosshole. In: II Encontro Regional de Geotecnia e Meio Ambiente e II Workshop de Geofísica Aplicada, Rio Claro-SP, SBGF/ABGE, CD-ROM, 3p.

Carvalho, M. F, 1999. Comportamento mecânico de resíduos sólidos urbanos. Tese de doutorado. Escola de Engenharia de São Carlos-USP, 300p.

Franco, H. A.; Rosa, J. W. C, 1995. Levantamento de refração sísmica no aterro sanitário de Brasília. In: $4^{\circ}$ Congresso Internacional da Sociedade Brasileira de Geofísica, São Paulo. Anais: Sociedade Brasileira de Geofísica, v.2, p.922-924.

IPT, 1998. Caracterização geológico-geotécnica, elaboração do projeto executivo de aterro sanitário e proposição de adequação da área do antigo aterro sanitário para encerramento e de diretrizes para o gerenciamento de resíduos sólidos no município de Itapira, SP. (Parecer Técnico № 7.157).
IPT, 2014. Elaboração de plano de encerramento do aterro sanitário de Itapira e estudos de viabilidade ambiental em área contígua. (Relatório Técnico $\mathrm{N}^{\circ}$ 137.171-205). 91p.

Kavazanjian Jr., E.; Snow, M. S.; Matasovic, N.; Poran, C. J.; Satoh, T, 1994. Non-intrusive Rayleigh wave investigations at solid waste landfills. Proceedings of the $1^{\text {nd }}$ International Congress on Environmental Geotechnics, Canada, v.1, p.707-712.

Kavazanjian Jr., E.; Matasovic, N.; Stokoe II, K. H.; Bray, J. B, 1996. In situ shear wave velocity of solid waste from surface wave measurements. Proceedings of the $2^{\text {nd }}$ International Congress on Environmental Geotechnics, Japan, v.1, p.97-102.

Malagutti Filho, W.; José, C.; Braga A. C. O.; Elis, V. R.; Tandel, R. Y.; Porsani, J. L, 1997. Aplicação integrada de técnicas geofísicas no aterro sanitário de Rio Claro - SP Resultados Preliminares. In: $5^{\circ}$ Congresso Internacional da Sociedade Brasileira de Geofísica, São Paulo. Anais: Sociedade Brasileira de Geofísica, v.1, p.422-425.

Pereira, A. G. H.; Mañas, L. S, 2001. Ensaios geofísicos e mecânicos realizados em um aterro de resíduos sólidos urbanos. In: $21^{\circ}$ Congresso Brasileiro de Engenharia Sanitária e Ambiental, 2001, João Pessoa-PB, 8p.

Rix, G. J.; Lai, C. G.; Foti, S. ; Zywicki, D, 1998. Surface wave tests in landfills and embankments. Geotechnical Earthquake Engineering and Soil Dynamics III, ASCE Geotechnical Special Publication no75, p.1008-1019.

Sahadewa, A.; Zekkos, D.; Lobbestael, A.; Woods, R. D, 2011. Shear wave velocity measurements at municipal solid waste landfills in Michigan. Pan-Am CGS Geotechnical Conference, Toronto.

http://geoserver.ing.puc.cl/info/conferences/PanAm2011/p anam2011/pdfs/GEO11Paper342.pdf

Strobbia, C., 2003. Surface wave methods: acquisition, processing and inversion, Ph.D. thesis, Politecnico di Torino, Italy.

Tandel, R. Y.; Malagutti Filho, W.; Tandel, M. C. F. $F, 1998$. Contribuição ao estudo da poluição provocada no aqüífero freático e no solo pelo aterro controlado da cidade de Rio Claro-SP. In: II Encontro Regional de Geotecnia e Meio Ambiente e II Workshop de Geofísica Aplicada, Rio Claro-SP, SBGF/ABGE, CD-ROM, 3p. 

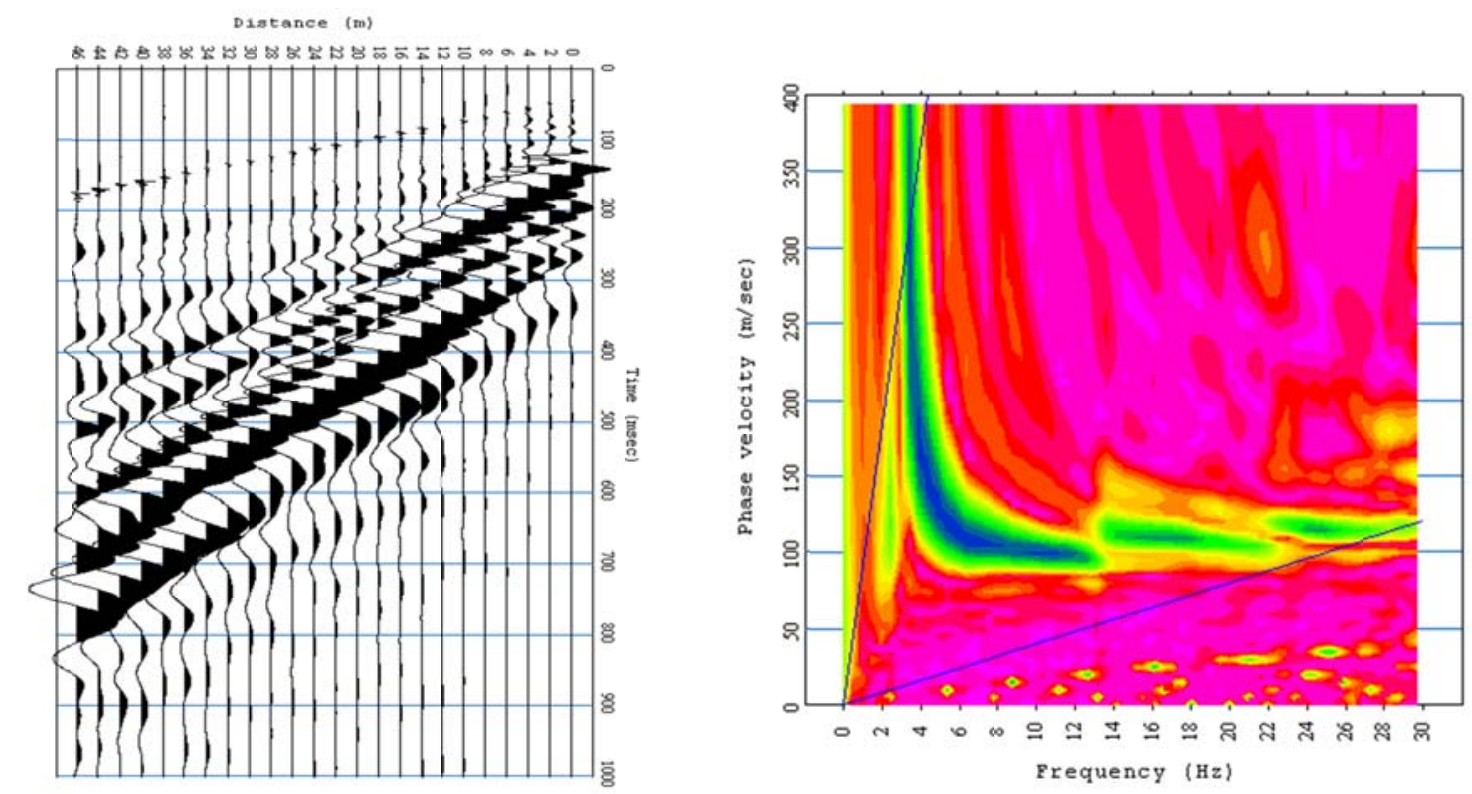

Figura 3 - Sismograma obtido no aterro de RSU (esquerda). Espectro de velocidades obtido do sismograma (direita).
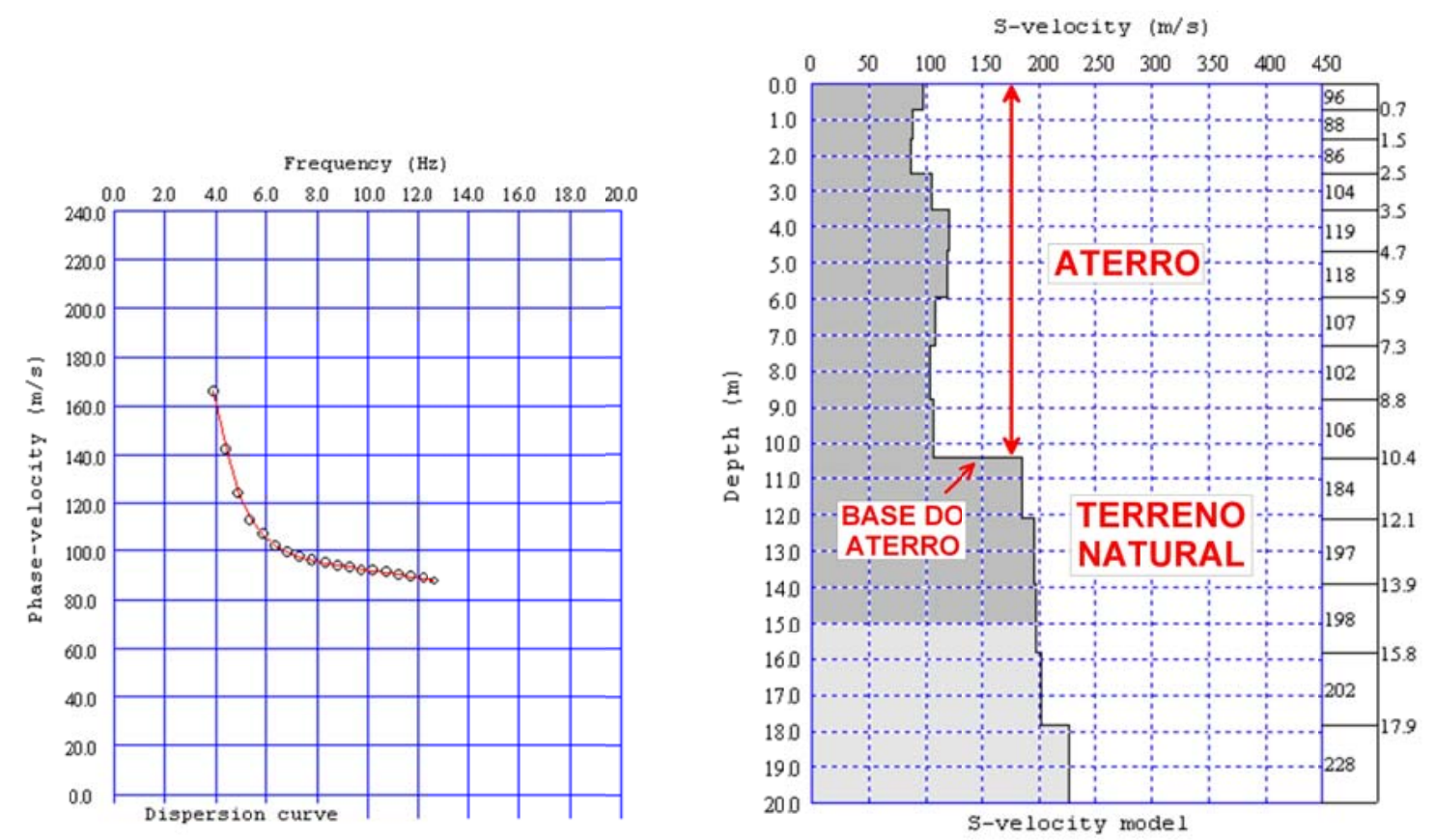

Figura 4 - Curva de dispersão interpretada (esquerda) e o modelo (velocidade da onda S x profundidade) resultante da inversão dos dados (direita). 